ELIGIBILITY

\title{
GUIDELINES FOR MANUSCRIPT SUBMISSION
}

At least one author must be a member of the NAREA.

SUBMISSION

Four copies of the manuscript should be submitted to:

Conrado M. Gempesaw II, Editor ARER

212 Townsend Hall

University of Delaware

Newark DE 19717

\section{COVER LETTER}

Indicate whether the material has been offered for publication, published in a similar form elsewhere, and so far as the author(s) knows, does not infringe upon other published material protected by copyright.

\section{TITLE PAGE AND ABSTRACT}

On the first page, list the title of the paper, the author(s), their title(s), department(s), institution(s), and complete address (including zip or postal code, if applicable). On the next page, list the title of the paper, an abstract not to exceed 100 words, and five or fewer key words describing the content of the manuscript. The author(s)' identification should not be repeated in the abstract or on other pages of the manuscript.

\section{TYPING}

The manuscript should be typed on $81^{\prime \prime} 2^{\prime \prime} \times 11^{\prime \prime}$ standard weight white paper with numbered lines (if possible), and all material, including references and footnotes, should be double-spaced.

\section{TABLES}

Each table should be on a separate page. Titles should be short and descriptive.

\section{FIGURES}

Prepare on heavy white paper using india ink or other materials suitable for photographic reproduction. Most will be reduced so typescript should be avoided.

\section{MATHEMATICAL NOTATION}

Use only essential notation and use standard type to the extent possible.

\section{FOOTNOTES}

In general, the use of footnotes should be avoided. Number them consecutively and type double-spaced on separate pages at the end of the manuscript.

\section{REFERENCES}

List references alphabetically and unnumbered on a separate page or pages at the end of the manuscript with the heading "References." Use the same format for references as is used in previous issues of this Journal. List only those actually cited. Refer to references by the names of the authors. Cite the year of the publication if an author has more than one reference cited. If there is more than one in a given year then use, for example, 1981a, $1981 \mathrm{~b}$. Authors can be referred to in the text parenthetically as (Smith) or (Jones 1981) or (Smith, p. 5), or the names can be used as part of a sentence such as "Smith and Jones maintain . . . ."

\section{REVIEW}

All manuscripts submitted will be refereed by the editorial board and others selected for their professional competence.

\section{PAGE CHARGE}

A page charge is billed to the department or agency after the article is accepted for publication.

\author{
PUBLISHED BY THE NORTHEASTERN AGRICULTURAL \\ AND RESOURCE ECONOMICS ASSOCIATION
}

PRINTED BY THE SHERIDAN PRESS, INC., HANOVER, PENNSYLVANIA 

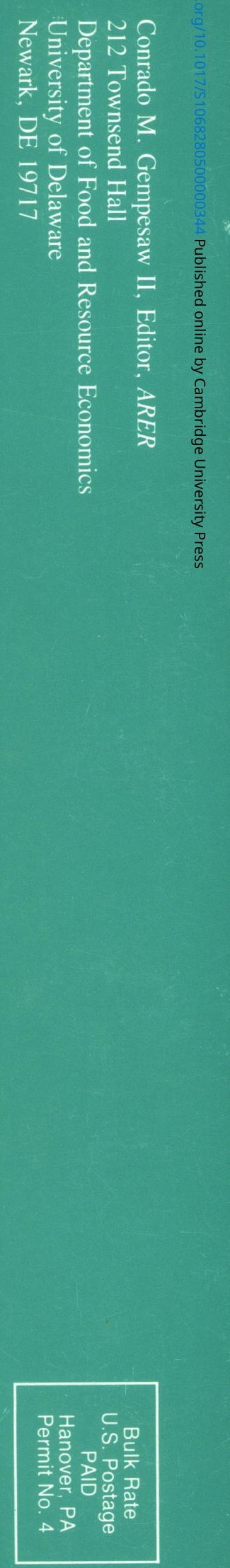